\title{
Ensayos
}

\section{El Porro, la cumbia y la gaita en los carnavales del Caribe Colombiano}

El Porro, cumbia and bagpipe in the carnivals of the Colombian Caribbean

Otero Ortega, Alfredo

alfredooteroortega@yahoo.es

ARQUITECTO - URBANISTA, Docente Catedrático en Universidades de la Región Caribe colombiana

\begin{abstract}
The cultural aspect and its exchange of the native and Spanish populations gave way to a series of celebrations and cultural processes that have been enriched since its origins in the $\mathrm{XV}$ century, which at that time had a religious focus and which later served as A means of communication of the people who became directly involved in these carnivals. Every year to the beat of cumbia, porro and bagpipe the battle of fun and organized disorder takes place where the comedies, comedies, disguises and dances cross the neighborhoods and streets in each town of the Colombian Caribbean. For this reason UNESCO has classified as tangible and intangible heritage of humanity.
\end{abstract}

Keywords

Cabildos, Folklore, Colombian Caribbean, Carnival.

\section{Resumen}

El aspecto cultural y su intercambio de las poblaciones autóctonas y las españolas, dio cabida a una serie de celebraciones y procesos culturales que se han ido enriqueciendo desde sus origene en el siglo XV, que tenían en ese momento un enfoque religioso y que sirvieron luego como un medio de comunicación de los pobladores que se involucraron directamente en estos carnavales. Cada año al compás de la cumbia, el porro y la gaita se realiza la batalla de jolgorio y desorden organizado en donde las comparsas, comedias, disfraces y danzas recorren los barrios y calles en cada pueblo del Caribe colombiano. Por esta razón la UNESCO ha catalogado como patrimonio tangible e intangible de la humanidad.

\section{Palabras Claves}

Cabildos, Folclor, Caribe Colombiano, Carnaval. 


\section{Desarrollo}

Los más de mil seiscientos kilómetros de longitud cultural y tradición que bordean las costas de esta prodigiosa región natural y política se bañan de procesos ancestrales que generación tras generación han forjado el carácter y entereza de hombres y mujeres que desde Cabo Tiburón en el Uraba a Cabo Castillete en la Guajira penetrando hacia el interior del Caribe colombiano hasta besar los andes no dejamos de ser espontáneos y calurosos con nuestro deber ser siendo reconocido así en el mundo entero.

Entre los muchos valores culturales y de tradición popular está el Carnaval, evento que por trashumancia se fue constituyendo en una forma de compartir los encuentros y despedidas en cada uno de los pueblos y caseríos del Caribe colombiano. Cabe decir, que desde el siglo XV en América se empezó a gestar este juego entre el bien y el mal como una manera de mofarse y hacer broma sobre los acontecimientos cotidianos del momento y teniendo en cuenta que esto fue traído por los colonizadores españoles bajo el mandato de Isabel la católica hay que referirse entonces, como un elemento religioso, puesto que guarda ciertas relaciones entre los días que anticipan la cuaresma en el calendario cristiano y el miércoles de ceniza como día primero antes del sacrificio de Jesús de Nazaret.

Este juego de máscaras y disfraces creció entre los nativos y negros esclavos y fue enriqueciéndose con las otras manifestaciones folclóricas y culturales propias del Caribe colombiano, como es el caso de la música de viento ejecutada desde las gaitas y flautas de millo hasta llegar a los instrumentos metálicos que hoy forman las bandas de músicos. Ese aporte autóctono del nativo en los ritmos y cadencias melodiosas hacen que tanto mascaras como disfraces empiecen a ser acompañados de danzas, cumbiambas, comparsas y grupos de bailarines que derrochan alegría al compás de las gaitas y tambores africanos.

El rico bagaje cultural y folclórico de cada uno de los pueblos del Caribe colombiano hacen posible que cada año al compás de la cumbia, el porro y la gaita nos transformemos y desarrollemos una batalla de jolgorio y desorden organizado en donde las comparsas, comedias, disfraces y danzas recorren los barrios y calles del pueblo luciendo sus vestidos y atuendos, pues serán el centro de atención durante estos cuatro días enfrentándose en un espectáculo agradable y que en su originalidad guarda como único premio sentirse orgulloso del trabajo artístico y folclórico creado y preparado entre todo el grupo haciendo de esto un rico sentido de pertenencia.

El carnaval también es música y aquí el porro, la cumbia y la gaita son melodías importantes para los grupos de danzantes que bailan y desfilan durante las carnestolendas. La música de viento representa un desembolso importante en las fiestas del rey Momo y su interpretación es la misma en el ambiente tradicional del pueblo como en el ámbito urbano de los tiempos modernos. 
Los músicos populares con su instrumento al hombre como herramienta de trabajo se preparan con anticipación para su larga jornada de ejecución musical durante el juego de carnaval.

De las sabanas de Sucre y Córdoba emigran por esos días carnestolendicos a Barranquilla, Santa Marta, Cartagena y otros lugares, para acompañar con sus melodías las danzas y comparsas de tradición popular formadas desde lo urbano.

Esta articulación de manifestaciones artísticas forjadas desde la cotidianeidad popular en cada pueblo del Caribe colombiano nos ha significado con orgullo la distinción de patrimonio tangible e intangible de la humanidad por la UNESCO.

Desde los cabildos de negros del siglo XVIII, que nos dejaron a los danzarines del Congo a la danza del torito como expresión autóctona, también encontramos diseminado por todo el Caribe colombiano el aporte de los Zenues, Chimilas, Arahuaco, Wuayuu, Mokaná y otras génesis indígenas que han sido determinantes en la creatividad artística y folclórica frente a la expresión coreográfica montada por cada grupo de danzantes y bailarines en donde la cumbia, ya sea cienaguera, sanpuesana, soledeña o sanjacintera, es uno de los mayores aportes a este juego entre el bien y el mal y su ejecución como danza y música representa uno de los valores primordiales aportados a este patrimonio tangible e intangible.

Y como la tradición pesa, iquien lo vive es quien lo goza!, razón por la cual donde hay juego de carnaval en cualquier rincón del Caribe colombiano una banda de músicos sabaneros interpretando porros, cumbias y gaitas animan el jolgorio. 